\title{
First experiments on ICRF discharge generation by a W7-X like antenna in the Uragan-2M stellarator
}

\author{
V.E. Moiseenko ${ }^{1} \uparrow$, Yu.V. Kovtun ${ }^{1}$, T. Wauters ${ }^{2}$, A. Goriaev ${ }^{2}$, \\ A.I. Lyssoivan ${ }^{2}$, A.V. Lozin ${ }^{1}$, R.O. Pavlichenko ${ }^{1}$, A.N. Shapoval ${ }^{1}$, \\ S.M. Maznichenko ${ }^{1}$, V.B. Korovin ${ }^{1}$, E.D. Kramskoy ${ }^{1}$, M.M. Kozulya ${ }^{1}$, \\ N.V. Zamanov ${ }^{1}$, Y.V. Siusko ${ }^{1}$, A.Yu. Krasiuk ${ }^{1}$, V.S. Romanov ${ }^{1}$, A. \\ Alonso $^{3}$, R. Brakel ${ }^{4}$, A. Dinklage ${ }^{4}$, D. Hartmann ${ }^{4}$, Ye. Kazakov², \\ H. Laqua ${ }^{4}$, J. Ongena ${ }^{2}$, T. Stange ${ }^{4}$, and the Uragan-2M Team
}

${ }^{1}$ Institute of Plasma Physics of the National Science Center "Kharkiv Institute of Physics and Technology", Kharkiv, Ukraine

${ }^{2}$ Laboratory for Plasma Physics, ERM/KMS, Brussels, Belgium

${ }^{3}$ Laboratorio Nacional de Fusion, CIEMAT, Madrid, Spain

${ }^{4}$ Max-Planck-Institut für Plasmaphysik, Greifswald, Germany

†Email address for correspondence: moiseenk@kipt.kharkov.ua

In support of the ICRF experiments planned for realization on the Wendelstein 7-X (W7-X) stellarator (wall conditioning, target plasma production, and heating), a first experimental study of a W7-X like two-strap antenna operation in the plasma production mode has been made in the Uragan-2M (U-2M) stellarator. For all the experiments, antenna monopole phasing was adopted. The W7-X like antenna operation with applied RF power of $\sim 100 \mathrm{~kW}$ have been performed in helium $\left(p=(4-14) \cdot 10^{-2} \mathrm{~Pa}\right)$ with the vessel walls pre-loaded with hydrogen. Production of plasma with a density higher than $10^{12}$ $\mathrm{cm}^{-3}$ was observed near the first harmonic of the hydrogen cyclotron frequency. Operation at first harmonic is feasible in $\mathrm{W} 7-\mathrm{X}$ future ICRF experiments. In experiments at $\mathrm{U}-2 \mathrm{M}$, a target ICRF plasma with the average density of $\sim(2-2.6) \cdot 10^{12} \mathrm{~cm}^{-3}$ was registered.

\section{Introduction}

The world biggest stellarator Wendelstein 7-X (W7-X) will resume its work in near years (KLINGER et al. 2019, Pedersen et al. 2019). The ion-cyclotron plasma heating (ICRH) system (ONGENA et al. 2014) will be installed at it among other new equipment.

The microwave heating at the $2^{\text {nd }}$ electron-cyclotron resonance (ECR) harmonics is the main mean for plasma production and heating at the W7-X device (WOLF et al. 2019). The working magnetic field range is mostly limited around the vicinity of $2.5 \mathrm{~T}$ value because the electron cyclotron resonance zone should be present inside the plasma column. There is an option to exploit the heating at $3^{\text {rd }}$ ECR harmonics in the magnetic field $1.7 \mathrm{~T}$ (ERCKMANN et al. 2007, MARUSHCHENKO et al. 
2019). Experiments at this magnetic field are of certain interest. First, they will give a possibility to determine the magnetic field influence on plasma confinement, plasma instabilities, equilibrium electric currents, etc. Second, since W7-X mechanical stresses are reduced in this case, more magnetic configurations are possible to be realized. Besides, the physics of the electron-cyclotron heating at $3^{\text {rd }}$ harmonics is of interest. The MHD stability studies (NÜHRENBERG 2016) and high-beta equilibrium investigations (GEIGER et al. 2015) need more magnetic configuration space of W7-X than it is available at $2.5 \mathrm{~T}$.

The first problem of operation at the low magnetic field $(1.7 \mathrm{~T})$ is plasma creation. While plasma creation is reliable at the $2^{\text {nd }}$ ECR harmonic, it is a problem at the $3^{\text {rd }}$ harmonic. An alternative possibility is an injection of fast neutral atoms which is available at W7-X. The calculations (GRADIC et al. 2015) show about 5 seconds delay between the neutral beam injection (NBI) start and full ionization of the neutral gas. This means that during that time almost all beam energy would be delivered to the armor installed at the opposite of the injector wall. The time of $5 \mathrm{~s}$ is excessively long and such a plasma production regime would result in unacceptably high thermal load onto the armor (PAUl VAN EETEN et al. 2019, ÄKÄSLOMPOLO et al. 2019).

The radio-frequency (RF) discharge becomes the only opportunity in such a situation. Calculations in the paper (GRADIC et al. 2015) point out that a successful plasma creation with the NBI for less than $0.5 \mathrm{~s}$ needs a target plasma with a density of $10^{10}-10^{11} \mathrm{~cm}^{-3}$. Other plasma parameters like temperature and ion composition are not very important. So, the creation of such a plasma is a minimum task for the RF discharge. After successful plasma production, the NBI heating increases plasma density and temperature (approximately to $500 \mathrm{eV}$ ) until the microwave beam can be effectively absorbed at $3^{\text {rd }}$ harmonic of ECR (MARUSHCHENKO et al. 2019).

Note that the RF heating equipment of $\mathrm{W} 7-\mathrm{X}$ has the wide frequency range, 25-38 MHz (ONGENA et al. 2014), which provides the ion cyclotron resonance for hydrogen ions inside the plasma column for $2.5 \mathrm{~T}$ and $1.7 \mathrm{~T}$ magnetic field. The RF heating equipment also gives a possibility of inner vacuum surfaces conditioning with hydrogen RF discharge or other chemically active gases.

....As for plasma production, a scenario was developed and used on Uragan devices with the frame antennas (LYSSOIVAN et al. 1992) and the frequencies below the ion cyclotron. This scenario does not fit well to W-7X since its ICRH antenna consists of two vertically oriented straps. The antennas with vertical straps are used at tokamaks for plasma production for wall conditioning purposes (see e.g., LI. et al. 2011). In those discharges the plasma density was below $1 \cdot 10^{12} \mathrm{~cm}^{-3}$ without full ionization. A bit higher plasma density and temperature was achieved in at W7-AS (BRAKEL et al. 2001) in a sophisticated two-step two-frequency scenario. Uragan-3M and Uragan-2M have the THT antennas (LOZIN et al. 2013, MoISEENKO et al. 2019) with the $\pi-0-\pi$ phased vertical straps. The experiments on plasma production with these antennas shown that they can produce plasma at lower magnetic field than the frame antenna when the frequency is equal to the ion cyclotron frequency. This plasma production scenario is characterized by a long gas breakdown time during which there is almost no antenna loading, and low temperature of plasma produced. So, for vertical strap antennas, there is a 
need for more efficient scenario of plasma production which besides plasma production gives an opportunity of successive plasma heating in the same pulse.

As the main gas for the experiments at Uragan-2M (U-2M), a helium is chosen since it is one of the working gases at W7-X (KLINGER et al. 2019). It is used in glow and ECR discharges for W7-X inner vacuum surfaces conditioning (WAUTERS et al. 2018). Helium ICR discharge was used earlier for vacuum chamber conditioning at W7-AS (BRAKEL et al. 2001), Tore Supra (GAUTHIER et al. 1997), TEXTOR-94 (ESSER et al. 1997), HT-7 (Hu et al. 2007) and EAST (Hu et al. 2008).

The goal is to research helium plasma creation in the U-2M stellarator device in the ion-cyclotron frequency range and to collect the information needed for W7-X plasma creation scenario development.

....The U-2M experimental setup is chosen to be mostly close to the W7-X. Note nere that both U-2M and W7-X are stellarators with topologically similar plasma column. The plasma confinement time is longer than plasma start-up time in both machines. The gas types and pressure ranges are similar. The plasma density is lower at U-2M, but still valuable for W-7X. For the experiments, a new W7-X-like antenna is installed at $\mathrm{U}-2 \mathrm{M}$ that has a $k_{\|}$spectrum of similar shape. The magnetic field module behaviour at the antenna place is important for the plasma start-up scenario chosen. The magnetic field module contours at the antenna location at U-2M are shown in Fig. 1. They are not much topologically different from the contours at W7-X (ONGENA et al. 2014).

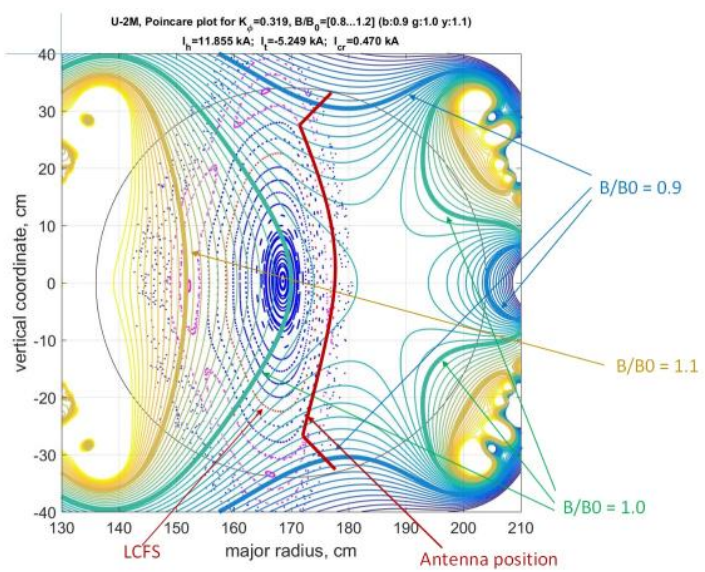

FIGURE 1. Poincare plot of magnetic configuration and contours of magnetic field module at U-2M in antenna location. The circular line shows the vacuum chamber wall.

The present paper gives the experimental results on plasma creation at U-2M with $\mathrm{W}-7 \mathrm{X}$ like antenna. The second section describes the device, the W-7X like antenna, the diagnostics, and the experimental conditions. The third section discusses the experimental results of plasma creation at the fundamental ion-cyclotron harmonic of hydrogen and gives some theoretical explanation to the experimental results. The Summary \& Conclusion section summarizes the obtained results. 


\section{Description of the experiment}

\subsection{Experimental setup}

The experiments on ICRF plasma build-up by the W7-X like antenna were carried out in the Uragan-2M stellarator type device (see PANKRATOV et al. 2010, MOISEENKO et al. 2011, VoITSENYA et al. 2014, MOISEENKO et al. 2016, 2017a). U-2M (see Fig. 2) was assembled in the early 90s (BYKOV et al. 1990, PAVLICHENKO 1993), operated briefly and then conserved. It was renewed and put to operation again at the end of 2006 (see MOISEENKO et al. 2007, BELETSKII et al. 2008).

The U-2M scheme is shown in Fig. 3. The major radius of the device is $R=1.7 \mathrm{~m}$, the average plasma radius is $r_{\mathrm{pl}}<24 \mathrm{~cm}$, the toroidal magnetic field at the toroidal axis at present is $B_{0}<0.6 \mathrm{~T}\left(B_{0}\right.$ $=B_{\mathrm{tt}}+B_{\mathrm{th}}, B_{\mathrm{tt}}$ and $B_{\mathrm{th}}$ are the toroidal fields produced by the toroidal and helical coils respectively, the maximum magnetic field with respect to the mechanical stresses is $B_{0}=2.4 \mathrm{~T}$ ). The $\mathrm{U}-2 \mathrm{M}$ magnetic system consists of $l=2$ helical coils with four periods $(m=4)$ in the toroidal direction. The minor radius of the helical coils is $r_{\mathrm{h}}=0.44 \mathrm{~m}$. The toroidal magnetic field is provided by a set of 16 circular toroidal coils evenly distributed along the torus. The poloidal coil system consists of 8 coils for elimination the vertical field induced by the helical coils: 4 trim (correcting) coils for control of the residual vertical field and 4 coils - for the magnetic island control. Two DC sources are used for power supply for the magnetic system. Each DC source consists of two generators P-22-33-17K with a peak power of $2750 \mathrm{~kW}$ each. The generators operated in a pulsed mode (see Fig. 4).

In the U-2M stellarator, the radio-frequency methods are used to create and heat the plasma. For this purpose, two RF systems are used: "Kaskad-1" (K-1) and "Kaskad-2" (K-2) (KoroviN \& KRAMSKOY 2012). Both systems operate independently. Each RF system includes the RF generator, the transmission line, the matching circuit, the antenna, and the control and diagnostic systems. The RF generators are single-staged. They have the push-pull generator design and use the GI-26A tubes. Pairs of the tubes are connected in parallel at each generator push-pull shoulder with a purpose to double the power output without increase of the anode voltage. The generators operate at a constant frequency in the range $3-15 \mathrm{MHz}$ and provide a pulse duration up to $100 \mathrm{~ms}$. The maximum output power of the generators is about 0.8 MW. The output of the generators is coaxial bipolar. Highfrequency energy from the generator is transferred to the antenna by the feeder line which consists of four coaxial cables: two in each generator shoulder (the radiofrequency cable RK-50-11-13 is used).

The toroidal vacuum chamber with the minor radius $r_{\mathrm{c}}=0.34 \mathrm{~m}$ has a volume $V_{\mathrm{c}}=3.88 \mathrm{~m}^{3}$ (without vacuum ports) and the inner surface area of $S=22.8 \mathrm{~m}^{2}$. There are 48 ports used for diagnostics, gas puffing, vacuum pumping, etc. The vacuum chamber is pumped by three turbo-molecular pumps TMN-500 (cross-sections V, Z1, V1 at Fig. 2), each one has the pumping speed of $0.5 \mathrm{~m}^{3} / \mathrm{s}$ and is equipped with a liquid $\mathrm{N}_{2}$ cryotrap aimed for trapping heavy gas molecules such as water and located between the pump and the vacuum chamber. Exhaust ends of the three turbo-molecular pumps are connected in parallel to the fore- vacuum pump AVZ-63D (the pumping speed is $0.063 \mathrm{~m}^{3} / \mathrm{s}$ ) through the nitrogen cryogenic trap. The ultimate residual pressure in the vacuum chamber is $1.1 \cdot 10^{-5} \mathrm{~Pa}$. There is a mass-spectrometer IPDO -2 of the omegatron type with the omegatron tube RMO-4S for the measurements of the residual gases partial pressures in the vacuum chamber. For the 
measurements of the total pressure in the vacuum vessel, the thermocouple (type PMT-2) and the ionization (type PMI-2 and PMM-32-1) pressure gauges are used. The puffing of the working gas into the vacuum chamber is made using the SNA-2 stationary gas puff system.

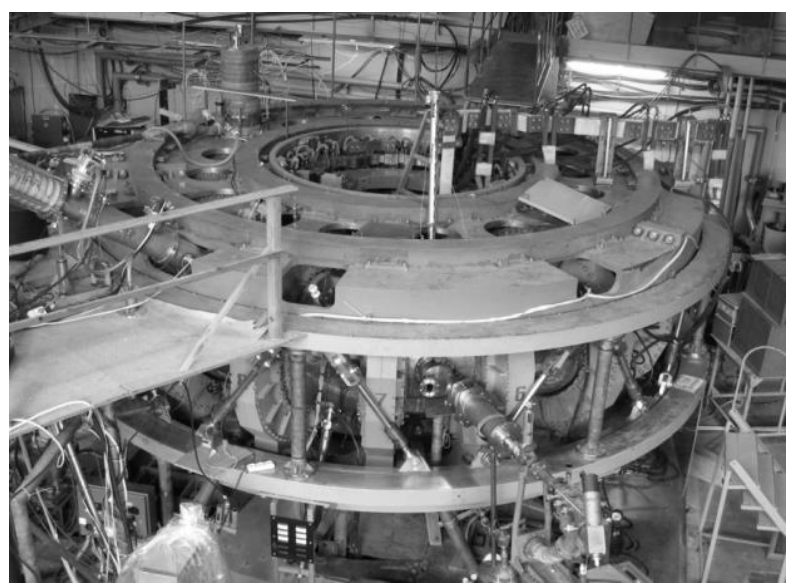

FIGURE 2. The Uragan-2M general view.

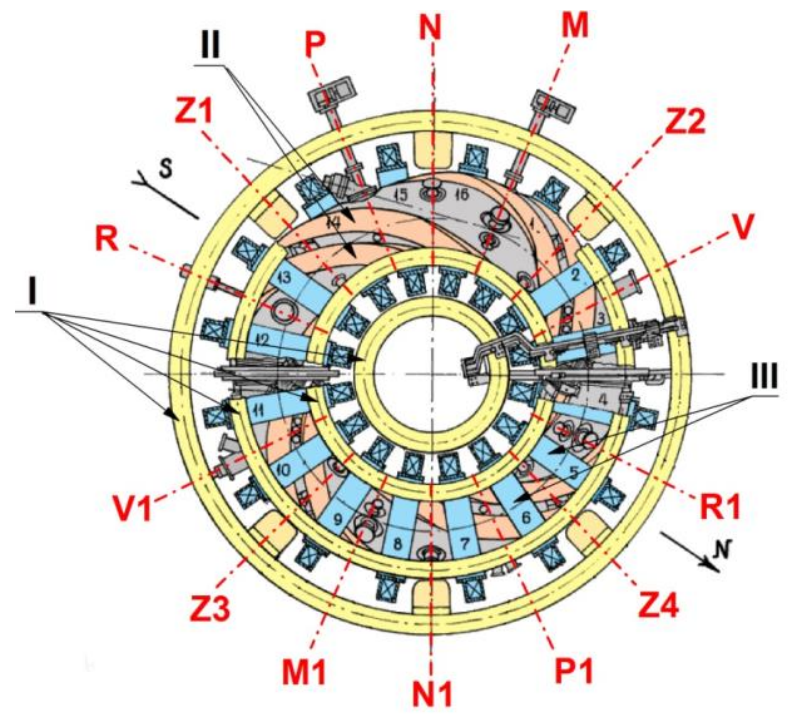

FIGURE 3. Scheme of Uragan-2M. I - Poloidal field coils; II - Helical field coils; III -Toroidal field coils numbered 1-16. Different toroidal cross-sections are shown in red and denoted by capital letters and numbers. 

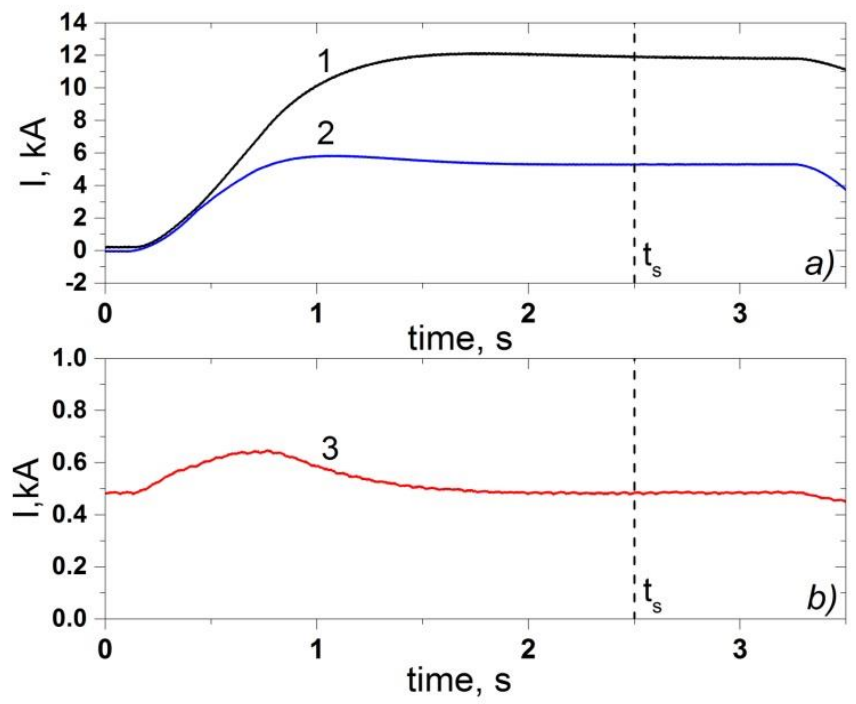

FIGURE 4. Time evolution of currents in helical $(\mathrm{a}, 1)$, toroidal $(\mathrm{a}, 2)$ and poloidal (correcting) $(\mathrm{b}, 3)$ coils of a magnetic system. $t_{\mathrm{s}}-$ start time of the RF generator.

\subsection{Two-strap antenna}

The U-2M has a history of ICRF plasma production and heating studies. The single and double frame, the crankshaft, the three-half-turn and the four-strap antennas (PANKRATOV et al. 2010, MOISEENKO et al. 2011, 2016, 2017a) were used in it.

....For plasma production studies, the existing vertical strap antenna, the THT antenna (MOISEENKO et al. 2019) could be used. However, the latter does not excite low $k_{\|}$waves, and this could be an obstacle for plasma production (LYSSOIVAN et al. 2012, 2014).

Recently a new two-strap antenna was designed and installed at the stellarator U-2M. This antenna is similar in shape to the ICRH antenna of the W-7X stellarator and differs from that one mainly by the smaller size. The antenna consists of two parallel poloidal straps (Fig. 5 a,b) made of stainless steel, $2 \mathrm{~mm}$ thick. The strap width is $60 \mathrm{~mm}$, and the length is $600 \mathrm{~mm}$. The antenna is installed in the cross-section R1 (Fig. 3). It is fitted to the last closed magnetic surface and placed at $10 \mathrm{~mm}$ distance from it (the magnetic configuration with $K_{\varphi}=0.32$ is used, where $K_{\varphi}=B_{\text {th }} /\left(B_{\mathrm{tt}}+B_{\mathrm{th}}\right)$ ) with two straps oriented perpendicular to the toroidal axis. A part of the plasma column comes too close to the antenna port, and at this place, the small limiters are inserted at the both sides of the antenna. The main antenna elements and limiters are covered with the titanium nitride film.

The two-strap antenna has four feeding points. The antenna can operate in different phasing (monopole and dipole) and connection schemes (grounded or floating). This, in contrast to the THT antenna, gives more possibilities to control antenna $k_{\|}$spectrum. The water cooling of its feedthroughs allows one to use the antenna in long ( 0.5 seconds) pulses. In the experiments reported here, the antenna operated in monopole phasing. 
One of the electric connection scheme for zero-phasing is presented in Fig. 5 c. To match the impedance of the feeder line to the antenna, a matching device with a bi-polar L-circuit was used (HAYWARD, WES, 1994). For the $\pi$-phasing, the serial connection of the straps is used.

....The RF power is calculated using the amplitudes of the forward and reflected waves in the feeder line measured by the directional coupler, according to formula:

$$
P_{R F}=\frac{1}{2} \cdot \frac{\left|U_{f}\right|^{2}}{Z_{0}}\left(1-|\Gamma|^{2}\right),
$$

where $Z_{0}$ is the impedance of the transmission line, $Z_{0}=25 \Omega,|\Gamma|$ is the reflection coefficient modulus, $|\Gamma|=\left|U_{r}\right| /\left|U_{f}\right|,\left|U_{f}\right|$ and $\left|U_{r}\right|$ the voltage modulus of the forward and reflected waves respectively.

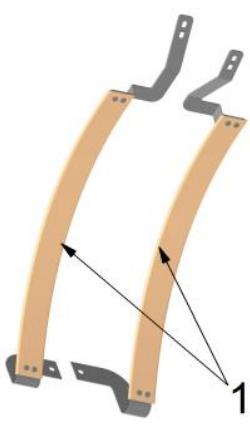

a)

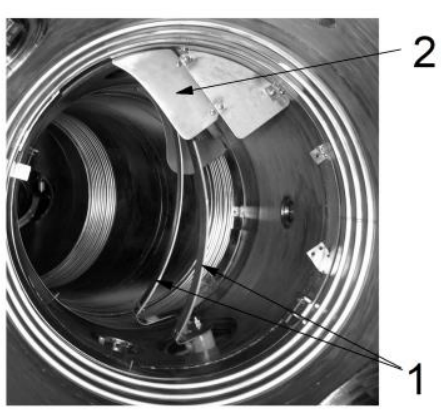

b)

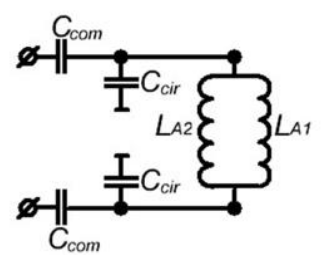

c)

FIGURE 5. Sketch of a two-strap antenna (a), two-strap antenna view in the U-2M vacuum chamber (1 - two-strap, 2 - limiter) (b), connection schemes ( $L_{A 1}$ and $L_{A 2}$ represent the antenna straps, $C_{\text {cir, }}$, $C_{\text {com }}$ are capacitors banks) (c).

\subsection{Diagnostic methods}

As for plasma diagnostics, the time dependence of the linear electron density (averaged over the line of sight) was measured using a microwave interferometer (PAVLICHENKO, ZAMANOV \& KULAGA 2017, 2018). The operational frequency of this superheterodyne interferometer equals to $140 \mathrm{GHz}$. The critical electron density for this frequency is $2.43 \cdot 10^{14} \mathrm{~cm}^{-3}$. The interferometer launches the ordinary polarized wave through the horizontal equatorial port along the minor axis of the elliptically shaped plasma in the cross-section $\mathrm{R}$ (see figure 3 ).

$\mathrm{U}-2 \mathrm{M}$ is equipped with the time-resolved optical emission spectroscopy (OES). OES was carried out using a monochromator-spectrograph SOLAR TII (SOL instruments Ltd.) model MS7501i (Cherny-Turner optical scheme) with a photomultiplier tube (PMT). The signals from the photomultiplier are amplified by a broadband amplifier and transmitted to the data acquisition system. The OES system has four independent channels. The database (KRAMIDA, RALCHENKO, READER, and NIST ASD Team 2019) was used to identify the optical emission lines of atoms and ions. Besides the 
integral emission registration, the scanning was made with 41 chords (see figure 6) in cross-section P1 (see figure 3). The chord distributions are measured using a pulse-by-pulse technique.

Signals from the microwave interferometer and OES system are transmitted via the fiber-optic transmission line to the data acquisition system. The data acquisition system of $\mathrm{U}-2 \mathrm{M}$ is based on the high-speed modules L-CARD E-20-10 (maximum acquisition frequency $10 \mathrm{MHz}$ ) and module LCARD L-783 which is used only for acquisition of the data from the RF directional coupler. The magnetic system, RF system, diagnostic equipment, and data acquisition system are synchronized the U-2M timing facility (LYASHCHENKO, et al. 2009).

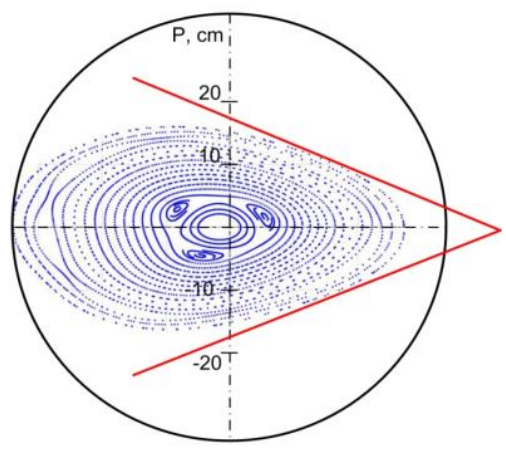

FIGURE 6. Sketch of chord measurements.

\section{Experimental results and discussion}

\subsection{Discharge characteristics}

Helium was chosen as working gas, and the hydrogen was always present during our experiments because of the U-2M vacuum chamber inner surfaces were pre-loaded with hydrogen . It is also produced of the residual water vapour and the absorbed at the wall hydrogen-containing impurities.

The experiments were carried out at the helium pressure $p=0.145 \mathrm{~Pa}$. The magnetic field value was $B_{0}=0.347 \mathrm{~T}, K_{\varphi}=0.32$, the current in the poloidal correcting coil was $I_{\text {corr }}=470 \mathrm{~A}$. The RF generator frequency was $f=5.15 \mathrm{MHz}$, while the hydrogen cyclotron frequency was $5.27 \mathrm{MHz}$ at the axis of the torus (in this case $\omega \approx \omega_{\mathrm{ci}}\left(\mathrm{H}^{+}\right) \approx 2 \omega_{\mathrm{ci}}\left(\mathrm{He}^{2+}\right) \approx 4 \omega_{\mathrm{ci}}\left(\mathrm{He}^{+}\right)$). Anode voltage was up to $7.5 \mathrm{kV}$. K-1 generator timing was $10 \mathrm{~ms}$ (start), $11 \mathrm{~ms}$ (step-1, the first power increase), $12 \mathrm{~ms}$ (step2 , the final power increase), $24 \mathrm{~ms}$ (shutdown). The RF generator anode voltage was varied stepwise: $U_{\mathrm{a} 1} \approx 0.4 \cdot U_{\mathrm{a}}$ at the start, $U_{\mathrm{a} 2} \approx 0.6 \cdot U_{\mathrm{a}}$ at the step- 1 and maximal anode voltage $U_{\mathrm{a}}$ was set at the step-2. 

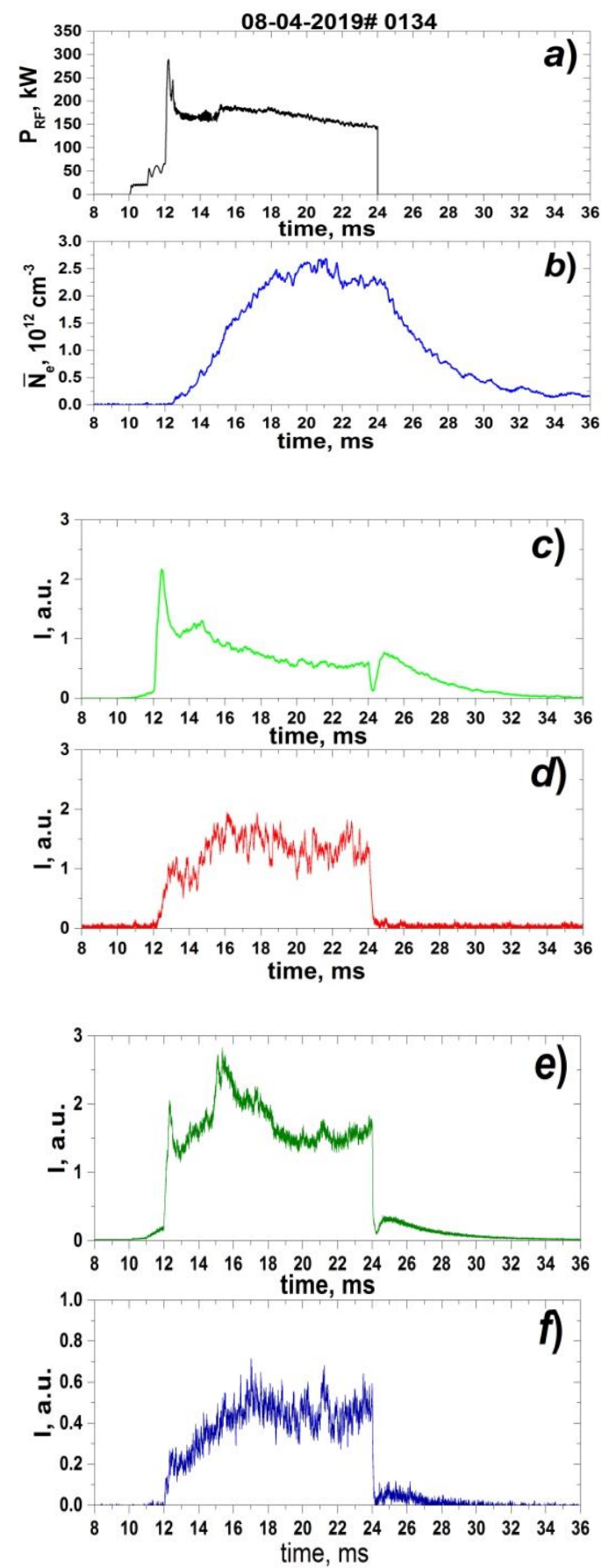

FIGURE 7. Time evolutions of RF powers (a); average plasma density (b); optical emission intensities of He I, $447.15 \mathrm{~nm}$ (c); He II, $468.6 \mathrm{~nm}$ (d); $\mathrm{H}_{\Delta}, 410.1 \mathrm{~nm}$ (e); O II, $441.5 \mathrm{~nm}$ (f) $\left(U_{\mathrm{a}}=\right.$ $7.5 \mathrm{kV})$.

The RF power, the average density, and the spectral line intensities are shown in Fig. 7. Three stages could be separated in this discharge. The first stage is the plasma creation (10-15 ms). Fig. 7 shows that the power transferred to the antenna varied significantly. $P_{R F}$ is $\sim 21 \mathrm{~kW}$ at the time interval of $10 \mathrm{~ms}$ (start) - $11 \mathrm{~ms}$ (step-1), $\mathrm{P}_{\mathrm{RF}}$ is $\sim 65 \mathrm{~kW}$ at time interval $11 \mathrm{~ms}$ (step-1) - $12 \mathrm{~ms}$ (step-2). The 
maximal power $\sim 290 \mathrm{~kW}$ is registered after $12 \mathrm{~ms}$ (step-2) and later decreases down to $\sim 160 \mathrm{~kW}$. The initial plasma creation and the plasma density growth sequentially occur at this stage (plasma creation initial stage is discussed in detail in subsection 3.2). The second stage (15-18 ms) is plasma density growth up to $2.4 \cdot 10^{12} \mathrm{~cm}^{-3}$. The excited atoms $\mathrm{H}^{*}\left(\mathrm{H}_{\Delta}\right), \mathrm{He}^{*}(\mathrm{He} \mathrm{I})$ spectral lines intensities decrease and excited ions $\mathrm{He}^{+*}\left(\mathrm{He}\right.$ II), $\mathrm{O}^{+*}$ (O II) spectral lines intensities increase until certain values. The power fed to the antenna is in the range of $160-190 \mathrm{~kW}$. The average plasma density changes in the range of $(2.2-2.6) \cdot 10^{12} \mathrm{~cm}^{-3}$ at the third stage, while power fed to antenna decreases from $184 \mathrm{~kW}$ to $140 \mathrm{~kW}$. The maximal average plasma density was $2.6 \cdot 10^{12} \mathrm{~cm}^{-3}$. Plasma decay begins after RF heating switch-off ( $24 \mathrm{~ms}$ ), plasma density and spectral lines intensity decreases. The average plasma density slowly ramps down with the characteristic time of about $\sim 4 \mathrm{~ms}$. He I, $\mathrm{H}_{\Delta}$ and $\mathrm{O}$ II spectral lines intensities increase during the certain time after RF heating switch-off, and He I afterglow is the most pronounced. It can be explained by electron temperature decrease and $\mathrm{He}^{+}, \mathrm{H}^{+}, \mathrm{O}^{2+}$ ions recombination with electrons. The absence He II spectral line afterglow is likely a result of the small $\mathrm{He}^{2+}$ ion concentration in plasma. The ionization energy threshold for $\mathrm{He}^{+}$ion is $54.4 \mathrm{eV}$, for $\mathrm{O}^{+}-$ $35.1 \mathrm{eV}$, for $\mathrm{He}-24.6 \mathrm{eV}$, for $\mathrm{H}-13.6 \mathrm{eV}$ (KRAMIDA, RALCHENKO, READER, and NIST ASD Team 2019). So, more effective $\mathrm{He}^{2+}$ ions generation by electron impact ionization requires a higher temperature than $\mathrm{O}^{2+}$ generation. Note that the spectral lines of the ions $\mathrm{O}^{4+}(\mathrm{OV}$, ionization energy threshold $113.9 \mathrm{eV})$ and $\mathrm{C}^{4+}(\mathrm{CV}$, ionization energy threshold $392.1 \mathrm{eV})$ were not detected in the experiments. This means that the electron mean energy is much less than the lowest above mentioned threshold.

Fig. 8 shows the dependency of the maximal average plasma density on the K-1 generator anode voltage. Plasma density doesn't exceed $1.2 \cdot 10^{12} \mathrm{~cm}^{-3}$ at voltages lower than $6.5 \mathrm{kV}$, while it is about $2 \cdot 10^{12} \mathrm{~cm}^{-3}$ at a higher voltage with weak dependency on it. Note that average plasma density was of the same order as in other experiments for RF plasma production (see, e.g. BRAKEL et al. 2001, ESSER et al. 1997).

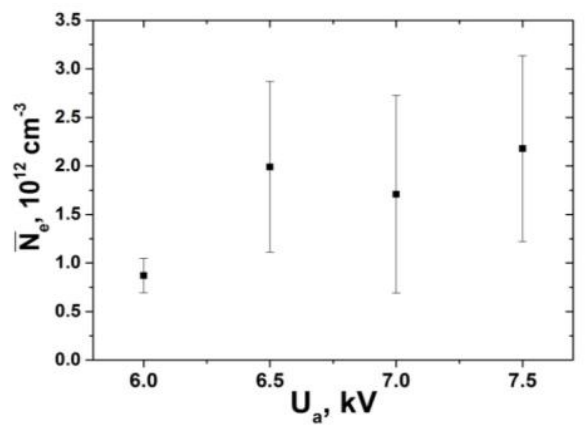

FIGURE 8. Dependence of maximum average plasma density as a function of the anode voltage on the generator K-1.

\subsection{Start-up details}


Research on the initial plasma creation stage of RF discharges in toroidal devices were carried out in experimental (ZALESKIJ et al. 1989, CARTER et al. 1990, LYSSOIVAN et al. 2005, MOISEENKO et al. 2017b, 2019) and theoretical (LYSSOIVAN et al. 1992, MOISEENKO et al. 2013, LYSSOIVAN et al. 2012, TRIPSKÝ et al. 2017, WAUTERS, T. et al. 2020) studies.

Following them, separate plasma creation stages can be identified. The first stage (non-wave stage) is the initial stage of plasma production. Here, the electromagnetic waves of ICRF don't propagate in toroidal vacuum vessels of fusion devices because of the low charged particle density $\omega_{\text {pe }}<\omega\left(\omega_{\text {pe }}-\right.$ electron plasma frequency) at this stage. Neutral gas is ionized by the electrons accelerated in RF antenna electric field. The resulting low-density plasma $\left(N_{\mathrm{e}} \ll N_{0}, N_{0}\right.$ - neutral particles density) propagates along the magnetic field lines and practically doesn't influence the electromagnetic field structure. Numerical simulations show the transition to a second stage when the wave propagation conditions are met $\omega_{\mathrm{pe}}>\omega$ (TRIPSKÝ et al. 2017), coinciding with an increase of the electron multiplication rate. Here, the plasma produced electrostatic field amplitude is of the same order as the vacuum $\mathbf{E}_{\|}$field of the antenna. Until here, the plasma is mostly created via electron impact ionization. These collisions are accompanied by a significant electron power loss which needs to be compensated via the RF power. At higher densities, the conditions given by the lower hybrid resonance $\omega^{2}=\omega_{\mathrm{pi}}{ }^{2}+\omega_{\mathrm{ci}}{ }^{2}$, the ion cyclotron resonance $\omega=\omega_{\mathrm{ci}}$ (ICR) and the fast wave cut-off density $\omega_{\mathrm{pi}}{ }^{2}=\left(N_{\|}{ }^{2}-1\right) \omega_{\mathrm{ci}}\left(\omega+\omega_{\mathrm{ci}}\right)$ determine the final radial extend of the discharge as well as the coupling efficiency of the RF power (LYSSOIVAN et al. 2012, LYSSOIVAN et al. 2014). Both electrons and ions are heated through collisional absorption of the electromagnetic waves, with additional possibility for resonant absorption on ions in the case of ICR.

The time of plasma creation can be associated with the time of excited atoms and ions appearance in the plasma $t_{\text {app. }}$ This is a time between RF pulse start-up and the start of the emission signal. Fig. 9 shows $t_{\text {app }}$ values for excited atoms (ions) of helium, hydrogen, and oxygen. $t_{\text {app }}$ is different for different lines and decreases with RF generator anode voltage increase, as it is seen in Fig. 9. The excited atoms have weaker dependence of $t_{\text {app. }}$ on $U_{\mathrm{a}}$ than the excited ions. The minimal values of $t_{\text {app }}$ are observed for the hydrogen atom line $\mathrm{H}_{\Delta}$ and $\mathrm{He} \mathrm{I}$ (Fig. 9a). $\mathrm{H}_{\Delta}$ has the value of $t_{\text {app }} \approx 0.13-0.2 \mathrm{~ms}$, and He I line $-t_{\text {app }} \approx 0.23-0.35 \mathrm{~ms}$ accordingly. The $t_{\text {app. }}$ difference between $\mathrm{H}_{\Delta}$ and $\mathrm{He} \mathrm{I}$ line is likely a result of different energy thresholds and cross-sections of excitation by the electron impact. For $\mathrm{H}_{\Delta} 410.1 \mathrm{~nm}$ and $\mathrm{He} \mathrm{I} 447.15 \mathrm{~nm}$ lines, the corresponding thresholds are $13.2 \mathrm{eV}$ и $23.7 \mathrm{eV}$ accordingly (KRAMIDA, RALCHENKO, READER, and NIST ASD Team 2019). Note that atomic hydrogen in ground or excited state appears in the discharge from electron impact with $\mathrm{H}_{2}$ and other molecules in the processes of dissociation, dissociative ionization and dissociative attachment (ITIKAWA 2001).

The experimentally obtained time $t_{\text {app }}$ for $\mathrm{H}$ and $\mathrm{He}$ I corresponds to the RF generator first (low power) time interval $10 \mathrm{~ms}$ (start) - $11 \mathrm{~ms}$ (step-1), so RF plasma production start-up occurs at this time interval and the second (wave) discharge stage begins. Then the plasma density increases, and the excited ion lines appear, first oxygen and then helium (Fig. 9b). The $t_{\text {app }}$ value is $\approx 1.4-2.3 \mathrm{~ms}$ for O II and is $\approx 1.9-2.6 \mathrm{~ms}$ for He II, respectively. The times $t_{\mathrm{app}}$. match different RF generator operation intervals depending of the anode voltage $U_{\mathrm{a}}$ (Fig. 9b). The difference of $t_{\text {app. }}$ for excited ions 
and atoms by the order of magnitude may be explained by a cascade ion excitation (KovTUN, ShAPOVAL \& SIUSKO 2019). The corresponding thresholds for the lines O II $441.5 \mathrm{~nm}$ and He II $468.6 \mathrm{~nm}$ are $26.3 \mathrm{eV}$ and $51.0 \mathrm{eV}$, accordingly (KRAMIDA, RALCHENKO, READER, and NIST ASD Team 2019). The oxygen atoms and ions appear in the discharge from electron impact excitation of $\mathrm{O}_{2}$ and other molecules (e.g. water) during dissociative processes (ITIKAWA 2001).

Some time after all the registered lines started to emit, the interferometer signal appears. Fig. 10 shows the dependencies of time delay needed for the average density to reach a certain value on the RF generator anode voltage. These are inverse dependences. They are weaker for low-density values and stronger for high. This is an indirect indication that the electron temperature decreases with the plasma density increase. As can be seen from the data obtained, the creation time of the average plasma density of $1 \cdot 10^{12} \mathrm{~cm}^{-3}$ is less than $10 \mathrm{~ms}$.

The times of appearance the optical line emissions and the times of reaching certain plasma density levels has a tendency to decrease with the anode voltage increase that is typical for the above shots. One can suggest that the electron temperature is higher for the higher anode voltage (at the same other conditions). So, the collision rate increases with the electron temperature that happens when the trend of the corresponding rate coefficients is positive. This occurs when the electron energy is not so high, below $200 \mathrm{eV}$ (the energy for the maximum electron impact ionization cross-section for helium (see SOROKIN et al. 2004)).
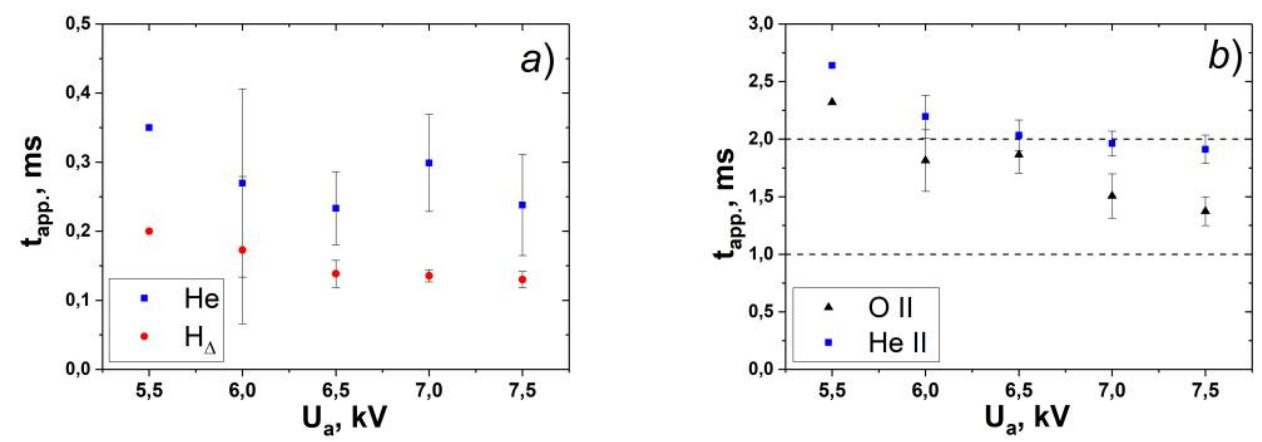

FIGURE 9. Time delay of spectral line emission appearing for the excited atoms He I $447.15 \mathrm{~nm}, \mathrm{H}_{\Delta}$ $410.1 \mathrm{~nm}$ (a) and the ions He II $468.6 \mathrm{~nm}$, O II $441.5 \mathrm{~nm}$ (b) as a function of the anode voltage on the generator K-1 (dashed lines show time step-1 and step-2).
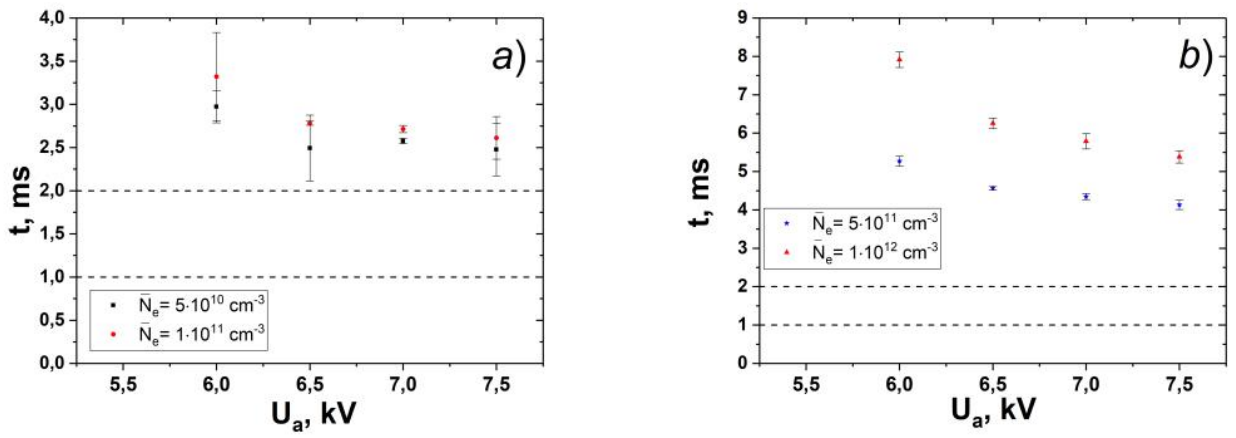
FIGURE 10. Time to reach average plasma density $5 \cdot 10^{10}$ and $1 \cdot 10^{11} \mathrm{~cm}^{-3}$ (a), $5 \cdot 10^{11}$ and $1 \cdot 10^{12} \mathrm{~cm}^{-3}$ (b) as a function of the anode voltage on the generator K-1 (dashed lines show time step-1 and step2).

\subsection{Chord measurements}

The chord measurements in a shot-by-shot regime for the lines He I and He II were carried out at the He pressure $p=0.145 \mathrm{~Pa}$; magnetic field at the device axis $B_{0}=0.347 \mathrm{~T}, K_{\varphi}=0.318$, poloidal correctional coils current $I_{\text {corr }}=447 \mathrm{~A}$ and K-1 generator frequency $f=5.13 \mathrm{MHz}$. The K-1 generator operated in the following scenario: $10 \mathrm{~ms}$ (start), $11 \mathrm{~ms}$ (step-1), $12 \mathrm{~ms}$ (step-2), $20 \mathrm{~ms}$ (shutdown), $U_{\mathrm{a}}=5 \mathrm{kV}$. The dependencies of RF power, average density and $\mathrm{H}_{\Delta}$ and $\mathrm{O}$ II spectral lines intensities for these conditions are shown in Fig. 11.

For this regime of plasma creation, the location of the chords with reference to the impact parameter is shown in Fig. 6. The measurement results are presented in Fig. 12. The drawings are of a similar shape despite the fact that in the first case a neutral helium atom emits, and in the second case - an ion. It follows from the figures $12 \mathrm{a}, \mathrm{b}$ that the radiation source has the same dimensions as the plasma column $(|\mathrm{P}|<18 \mathrm{~cm})$, with the ion luminescence region being somewhat smaller than that one of the atom. It is also seen that the emission of the He I and He II lines along the chords changes in time, and the dependence of the line intensities on the impact parameter is not symmetric. Note that the average plasma density also changes with time (see fig. 11b). Because the plasma production is transient and could be accompanied by plasma non-uniformity along the flux surface, conclusions on the profile shapes are hard to make.
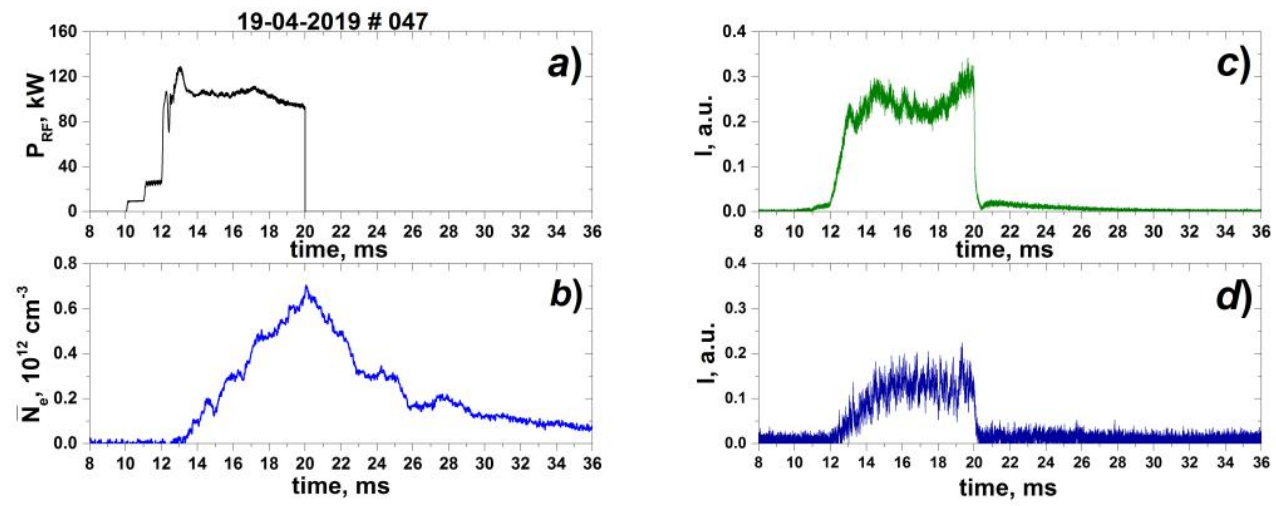

FIGURE 11. Time evolutions of RF powers (a); average plasma density (b); optical emission intensities of $\mathrm{H}_{\Delta}, 410.1 \mathrm{~nm}(\mathrm{c})$; O II, $441.5 \mathrm{~nm}(\mathrm{~d})\left(U_{\mathrm{a}}=6 \mathrm{kV}\right)$. 


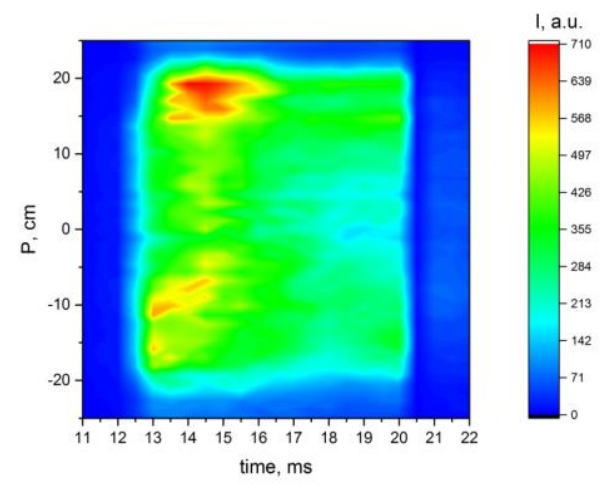

a)

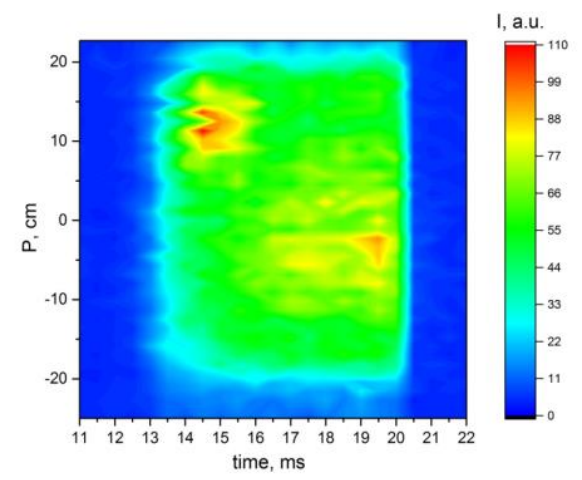

b)

FIGURE 12. Time evolution of He I (a) and He II (b) chord distribution. He I wavelength is $447.15 \mathrm{~nm}$, He II wavelength is $468.6 \mathrm{~nm}$. P - impact parameter (see fig. 5).

\subsection{Discussion of Wave Propagation}

In the scenario studied, presence of the hydrogen ion cyclotron zone is necessary. Otherwise, the density of plasma produced is lower by orders of magnitude. This allows one to suggest a significant role of the hydrogen ions in the plasma creation process. Plasma creation can occur with ion impact ionization (MoISEENKO, 1980). High ion energy is needed in such a case to effectively ionize the neutral gas; the helium ions ionization cross-section is $10^{-17} \mathrm{~cm}^{2}$ for $10 \mathrm{keV}$ protons (JANEV et al. 1987). Also, indirect plasma creation is possible when the hot ions heat the electrons via Coulomb collisions and, then, the electrons ionize the neutral gas. This mechanism is similar to that one taking place at plasma creation with the neutral beam injection. Such a mechanism provides slow plasma creation and the bottleneck is low ion-electron collision rate (KANEKO et al. 2002, GRADIC et al. 2015). In our experiments, the plasma generation delay is small. This means that the electrons got energy directly from the RF field.

The RF heating of electrons is connected with the wave processes in the plasma. The helium majority ions generally determine the plasma dielectric response on the RF field. The ion cyclotron frequency for both singly and doubly ionized helium is lower than the RF frequency. The fast magneto sonic wave (FMSW) is propagating in such conditions. It is absorbed poorly by the cold plasma electrons but can be absorbed in the cyclotron resonance zone for the minority hydrogen ions.

The two-strap poloidal antenna can excite the slow wave (SW) to less extent as compared to FMSW. However, SW can play an important role in the plasma production process. Its dispersion equation reads: 
$k_{\perp}^{2}=-\frac{\varepsilon_{\|}}{\varepsilon_{\perp}}\left(k_{\|}^{2}-k_{0}^{2} \varepsilon_{\perp}\right)$

Here $k_{\|}=\mathbf{k} \cdot \mathbf{B} / B, k_{\perp}^{2}=k^{2}-k_{\|}^{2}, \varepsilon_{\|}=\mathbf{B} \cdot \hat{\mathbf{\varepsilon}} \cdot \mathbf{B} / B^{2}, \varepsilon_{\perp}=(\mathbf{r} \times \mathbf{B}) \cdot \hat{\varepsilon} \cdot(\mathbf{r} \times \mathbf{B}) / \mathbf{r} \times\left.\mathbf{B}\right|^{2}, \hat{\varepsilon}$ - plasma dielectric tensor, $\mathbf{r}$ - radius-vector, $\mathbf{B}$ - magnetic field vector. The longitudinal tensor component $\varepsilon_{\|}<0$ in a cold plasma, and SW can propagate in plasma () where $\varepsilon_{\perp}>0$. The slow wave can be damped due to the imaginary part of $\varepsilon_{\|}$and in this case delivers its energy to the plasma electrons (LYSSOIVAN et al, 1992). The imaginary part appears owing to the electron binary collisions, mainly with the neutral gas. A contribution to the imaginary part is also made by the Landau damping on electrons, especially at low RF generator frequencies.

Fig. 13 displays a drawing of the $\varepsilon_{\perp}$ behavior along the major radial chord. There are 3 zones of SW propagation: two are at the plasma edge and one in the center of the plasma column. All 3 zones are ended with zero-valued $\varepsilon_{\perp}$. When $\varepsilon_{\perp} \rightarrow \pm 0$, the following (2), $k_{\perp}^{2} \rightarrow \pm \infty$, and this is the lower hybrid resonance point. The SW travels in direction opposite to the $\varepsilon_{\perp}$ gradient and reaches lower hybrid resonance point where it is fully damped without reflections (FIDONE \& GRANATA 1971, MoISEENKo, WAUTERS \& LysSOIVAN 2016). At two SW propagation zones at the plasma edge, the plasma properties are determined by the majority ions, helium, and the plasma density corresponding to the lower hybrid resonance can be estimated as $N_{\mathrm{e}} \approx 3 \cdot 10^{9} \mathrm{~cm}^{-3}$ for $5.1 \mathrm{MHz}$ generator frequency. One can suggest that the SW propagation zone near the antenna provides plasma production at the early stage of the RF discharge (LYSSOIVAN et al, 2014).

Two-strap antenna excites waves with a broad $k_{\|}$spectrum. If $k_{\|}$is large enough, $k_{\|}>\omega / v_{t h, e}$ (here $v_{t h, e}$ - thermal electron speed), then $\varepsilon_{\|}$changes its sign from negative to positive. The wave propagates inside the plasma column in such a case where $\varepsilon_{\perp}<0$, and is absorbed by plasma electrons with Landau mechanism. The zone between the antenna and the lower hybrid resonance point becomes then the zone of cut-off, and the wave tunnelling comes to play. On plasma density increase, the lower hybrid resonance point shifts closer to the antenna, and the tunnelling becomes better together with the antenna - wave coupling.

A more powerful plasma heating mechanism appears when there is a hydrogen cyclotron resonance zone inside the plasma column. The minority contribution to $\varepsilon_{\perp}, \varepsilon_{\perp \mathrm{H}}$, has a singularity at the point of ion cyclotron resonance which is canceled by the collision frequency or the Doppler shift. At higher magnetic field than the resonant one, $\varepsilon_{\perp \mathrm{H}}>0$ and its value can exceed the negative contribution of the majority ions. There, the SW propagation zone appears. It is bounded by the lower hybrid resonance from the left (see Fig.13) and a cut-off point from the right which obeys the condition $\varepsilon_{\perp}=\left(k_{\|} / k_{0}\right)^{2}$ that can be obtained from Eq. (2). The cut-off point for SW is the conversion point (Alfvén resonance, AR) of FMSW to SW. The generated by the FMSW field slow wave propagates inside the torus according to (1), reaches the point of low hybrid resonance (LHR) where it is totally absorbed (KLIMA, LONGINOV \& STEPANOV 1975). 
In 2D and 3D non-uniform plasma the electron heating pattern is more complicated. Following the papers (Hellsten \& TENNFORS 1984, MOISEENKO \& TENNFORS 1996), in the limit of infinite conductivity of plasma along the magnetic field lines, the conversion occurs near the magnetic surface. The case of finite conductivity was treated numerically in 2D for tokamaks (see, e.g. LIN et al 2003). Even in qualitative sense, the results are doubtfully applicable for our case since the calculations were done for hot fully ionized plasma with the temperature about two orders of magnitude higher than in our experiment.

For efficient conversion, it is necessary that this magnetic surface not to intersect the cyclotron zone. Such a heating scheme needs to choose heating frequency lower than ion cyclotron one at the device axis (see Fig. 14). This is confirmed in our experiment.

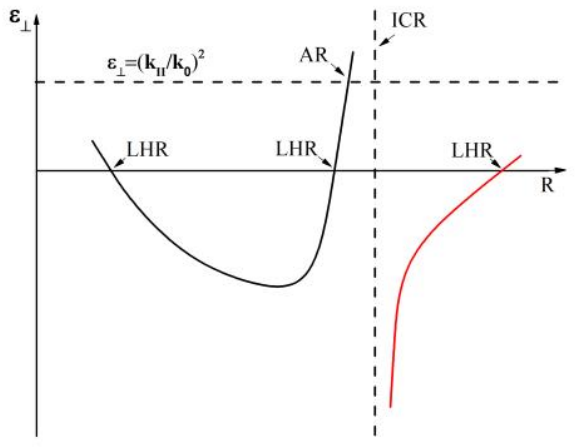

FIGURE 13. Sketch of $\varepsilon_{\perp}$ behavior along the major radial chord.

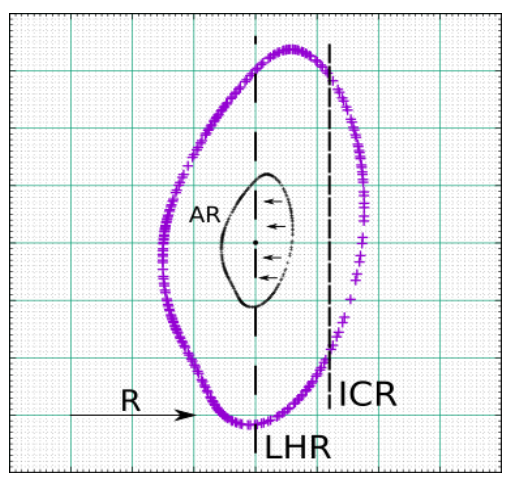

FIGURE 14. Sketch illustrates FMSW conversion into SW in the presence of small dope ICR inside the plasma column.

It is necessary to note that above described scenario was developed initially for plasma heating and successfully used for this (see, e.g. MAJESKI et al. 1996). So, after plasma production, with higher RF power the scenario could continue for plasma heating. 


\section{Summary \& Conclusion}

In support of the ICRF experiments planned for realization on the W7-X stellarator (wall conditioning, target plasma production, and heating), a first experimental study of a W7-X like twostrap antenna operation in the plasma production mode has been performed in the U-2M stellarator. The first experimental results of ICRF discharges created with the W7-X like antenna in certain regimes are presented in this paper. For all the experiments, antenna phasing is a monopole. The W7$\mathrm{X}$ like antenna operation with applied RF power of $\sim 100 \mathrm{~kW}$ have been performed in helium $\left(p=(4-14) \cdot 10^{-2} \mathrm{~Pa}\right)$ with the vessel walls pre-loaded with hydrogen. Production of plasma with a density higher than $10^{11} \mathrm{~cm}^{-3}$ was observed near the fundamental harmonic of the hydrogen cyclotron frequency. Operation at first hydrogen harmonic is feasible in W7-X future ICRF experiments. In experiments at U-2M, a target ICRF plasma with the average density of $\sim(2-2.6) \cdot 10^{12} \mathrm{~cm}^{-3}$ was registered.

The discharges of such type are described, and the three stages of discharge development are identified. The dependences of measured quantities on the discharge parameters are analysed. The dependence of the final average plasma density on the generator anode voltage (the launched power) saturates at high voltage values. Analysis of the OES data reveals that after the RF power launch, first appears $\mathrm{H}_{\Delta}$ line, then with small delay He I line. Delay for He II and O II lines is quite long and becomes shorter with RF power increase. The rate of plasma production is almost independent of the launched RF power at the initial plasma production stage and increases with power at further stages. The radial distribution of $\mathrm{He}$ I and $\mathrm{He}$ II lines luminosity are almost similar.

In the RF plasma production scenarios, RF generator operation without load is unavoidable. This happens at the initial stage of plasma production and could result in arcing. If the no-load stage is short, the probability of arcing reduces to negligible values. In the scenario of plasma build-up studied, the no-load time is very small, $2 \div 3 \mathrm{~ms}$. For example, at W7-X the no-load time for the ECRH generators is limited by $50 \mathrm{~ms}$.

Short plasma production time indicates that at all stages of plasma production the electrons are intensively heated by the RF field. The slow wave possibly plays a key role in this. At the initial stage of plasma production, the direct slow wave excitation by the antenna comes to play. At higher plasma densities, the mode conversion minority scenario of electron heating is realized.

The studied plasma production scenario looks promising and can possibly be used at bigger than the $\mathrm{U}-2 \mathrm{M}$ machines. The minority of hydrogen at helium atmosphere is possible at $\mathrm{W}-7 \mathrm{X}$ and the RF power at $26 \mathrm{MHz}$ is available for the magnetic field $1.7 \mathrm{~T}$. The topologies of the magnetic field module at the antenna locations in U-2M and W7-X are not so different. Also, the structure of antenna currents is similar. If such a scenario would be realized at W7-X, a higher RF power is necessary. One can suggest that the power is proportional to the plasma volume. Under this assumption, the necessary ICRH power is $0.9-1.8 \mathrm{MW}$. Such a power will be available at W7-X.

The same can be said about the experiment on LHD (KOMORI et al. 2010). There, for the RF frequency of $38.5 \mathrm{MHz}, 2.6 \mathrm{~T}$ magnetic field is available. 


\section{Acknowledgements}

This work has been carried out within the framework of the EUROfusion Consortium and has received funding from the Euratom research and training programme 2014-2018 and 2019-2020 under Grant Agreement No. 633053. The views and opinions expressed herein do not necessarily reflect those of the European Commission.

This work also received funding from National Academy of Sciences of Ukraine (grants P-3-22, and TsV-5-20).

\section{REFERENCES}

ÄKÄSLOMPOLO, S. et al. 2019 Validating fast-ion wall-load IR analysis-methods against W7X NBI empty-torus experiment. JINST 14, P07018.

BeLETSKII, A. A. et al. 2008 First results of the renewed URAGAN-2M torsatron. Problems of Atomic Science and Technology. Ser.: Plasma Phys. 6, 13-15.

BRAKEL, R. et al. 2001 ICRF wall conditioning experiments in the W7-AS stellarator. J. Nucl. Mater. 290, 1160-1164.

BYKOV, V. E. et al. 1990 URAGAN-2M: a torsatron with an additional toroidal field. Fusion Technology. 17, 140-147.

CARTER, M. D. et al. 1990 Plasma production using radiofrequency fields near or below the ion cyclotron range of frequencies. Nucl. Fusion 30, 723-730.

ERCKMANN, V. et al. 2007 Electron Cyclotron Heating for W7-X: Physics and Technology. Fusion Sci. Technol 52, 291.

ESSER, H. G. et al. 1997 ICRF wall conditioning at TEXTOR-94 in the presence of a $2.25 \mathrm{~T}$ magnetic field. J. Nucl. Mater. 241, 861-866.

FIDONE, I. \& GRANATA, G. 1971 Propagation of electromagnetic waves in a plasma with a sheared magnetic field. Nucl. Fusion 11, 133 - 139.

GAUTHIER, E. et al. 1997 Wall conditioning technique development in Tore Supra with permanent magnetic field by ICRF wave injection. J. Nucl. Mater. 241, 553-558.

GEIGER, J et al 2015 Physics in the magnetic configuration space of W7-X. Plasma Phys. Control. Fusion 57014004

GRADIC, D. et al. 2015 Assessment of the plasma start-up in Wendelstein 7-X with neutral beam injection. Nucl. Fusion 55, 033002.

HAYWARD, Wes, 1994 Introduction to Radio Frquency Design. ARRL. p. 138. ISBN 0-87259-492-0.

Hellsten, T. \& TenNFORS, E. 1984 Resonance Surfaces in the Ion Cyclotron Frequency Range in Toroidal Systems. Phys. Scr. 30, 341-345.

HU, J. S. et al. 2007 Differences of ICR cleanings in $\mathrm{He}, \mathrm{D}_{2}$ and $\mathrm{O}_{2}$ for deposit removal and hydrogen release in HT-7. J. Nucl. Mater. 366, 206-215.

HU, J. S. et al. 2008 He-ICR cleanings on full metallic walls in EAST full superconducting tokamak. J. Nucl. Mater. 376, 207-210.

ITIKAWA, Y. (ed.) 2001 Elementary Particles, Nuclei and AtomsVolume 17. Photon and 
Electron Interactions with Atoms, Molecules and Ions. Subvolume C. Interactions of Photons and Electrons with Molecules. Springer-Verlag Berlin Heidelberg.

JANEV R. K. et al. 1987 Elementary Processes in Hydrogen-Helium Plasmas. Cross Sections and Reaction Rate Coefficients. Springer-Verlag.

KANEKO, O. et al. 2002 Analysis of plasma initiation by neutral beams in the Large Helical Device. Nucl. Fusion 42, 441-447.

Klima, R., Longinov, A. V. \& Stepanov, K. N. 1975 High-frequency heating of plasma with two ion species. Nucl. Fusion 15, 1157-1171.

KLINGER, T. et al. 2019 Overview of first Wendelstein 7-X high-performance operation. Nucl. Fusion 59, 112004.

KomorI, A. et al. $2010 \mathrm{Goal}$ and achievements of large helical device project Fusion Science and Technology 58, 1.

Kovtun Yu.V., Shapoval A.N. \& SiUsKo Y.V. 2019 Observation of multiply charged states ions in a high-power pulsed reflex discharge. Plasma Sources Sci. Technol. 28, 105009.

Korovin, V. B. \& KRAMSKOY, E. D. 2012 Radio-frequency equipment for Uragan stellarators. Problems of Atomic Science and Technology. Ser.: Plasma Phys. 6, 19-21.

KramidA, A., RalchenKo, Yu., ReAdER, J., and NIST ASD Team. 2019 NIST Atomic Spectra Database (ver. 5.7.1).

LI, J. et al 2011 Wall conditioning towards the utilization in ITER. J. Nucl. Mat. 415, S35.

LIN, Y. et al 2003 Ion cyclotron range of frequencies mode conversion electron heating in deuterium-hydrogen plasmas in the Alcator C-Mod tokamak. Plasma Phys. Control. Fusion 45, 1013.

LOZIN, A.V. et al. 2013 Usage of Three-Halfturn Antenna at the Uragan-3M Device.

Problems of Atomic Science and Technology. Ser.: Plasma Phys (83). № 1, 27-29.

LYASHCHENKO, V.N. et al. 2009 Synchronization system for experiments research installation Uragan-2M. The Journal of Kharkiv National University. Physical series "Nuclei, Particles, Fields”. 880, 113-119.

LYSSOIVAN, A. I et al. 1992 Analysis of ICRF $\left(\omega<\omega_{\text {ci }}\right)$ plasma production in large scale tokamaks. Nucl. Fusion 32, 1361-1372.

LYSSOIVAN, A. et al. 2005 Development of ICRF wall conditioning technique on divertortype tokamaks ASDEX Upgrade and JET. J. Nucl. Mater. 337, 456-460.

LYSSOIVAN, A. et al. 2012 Simulation of ITER full-field ICWC scenario in JET: RF physics aspects. Plasma Phys. Control. Fusion 54, 074014.

LYSSOIVAN, A. et al. 2014 Wave aspect of neutral gas breakdown with ICRF antenna in ICWC operation mode. 41st EPS Conference on Plasma Physics. Vol. 38. P2.030.

MAJESKI, R. et al. 1996 Mode Conversion Heating and Current Drive Experiments in TFTR. Phys. Rev. Lett. 76, 764.

MARUSHCHENKO, N. B. et al. 2019 Reduced field Scenario with X3 heating in W7-X. EPJ Web of Conferences 203, 01006.

MoiseEnKo, V. E. 1980 RF Breakdown of a Neutral Gas by Means of Ions. Fiz. Plazmy 6, 1174-1178. (in Russian)

MoiseenKo, V. E. et al. 1993 Fast Wave Minority Heating in an Open Trap. Nucl. Fusion 33, 
565-579.

MoISEENKO, V. E. \& TENNFORS, E. 1996 Localized global ICRF eigenmodes and conversion zones in a two-ion species tokamak. Plasma Phys. Control. Fusion 38, 2133-2142.

MoISEENKO, V. E. et al. 2007 RF Plasma Production in Uragan-2M Torsatron. AIP Conf. Proc. 933, 115-118.

MOISEENKO, V. E. et al. 2011 RF plasma production and heating below ion-cyclotron frequencies in Uragan torsatrons. Nucl. Fusion 51, 083036.

MoISEENKO, V. E. et al. 2013 Self-consistent modeling of radio-frequency plasma generation in stellarators. Plasma Phys. Rep. 39, 873-881.

MoISEENKO, V. E. et al. 2016 Progress in stellarator research at IPP-Kharkov. Nukleonika 61, 91-97.

MoiseenKo, V. E., WAUTERs, T. \& Lyssoivan, A. 2016 Lower hybrid resonance: field structure and numerical modelling. Problems of Atomic Science and Technology. Ser.: Plasma Phys. 6, 44-47.

MoiseEnKO, V. E. et al. 2017a Alfven Plasma Heating in Stellarator Uragan-2M. Ukrainian Journal of Physics 62, 311-311.

MoISEENKO, V. E. et al. 2017b Radio-frequency plasma start-up at Uragan-3M stellarator. Problems of Atomic Science and Technology. Ser.: Plasma Phys. 1, 54-59.

MoiseEnKo, V. E. et al. 2019 Three half-turn antennas start-up. Problems of Atomic Science and Technology. Ser.: Plasma Phys. 1, 263-266.

NÜHRENBERG, C. 2016 Free-boundary ideal MHD stability of W7-X divertor. Nucl. Fusion 56,076010

ONGENA, J. et al. 2014 Study and design of the ion cyclotron resonance heating system for the stellarator Wendelstein 7-X. Phys. Plasmas 21, 061514.

PANKRATOV, I. M. et al. 2010 Behavior of RF Discharge Plasmas in the Uragan-3M and Uragan-2M Torsatrons. Contrib. Plasma Phys. 50, 520-528.

PAVLICHENKO, O. S. 1993 First results from the URAGAN-2M torsatron. Plasma Phys. Control. Fusion 35, B223- B230.

Pavlichenko, R. O., Zamanov, N. V. \& Kulaga, A. E. 2017 First measurements of line electron density in Uragan-2M plasmas via $140 \mathrm{GHz}$ heterodyne interferometer. Problems of Atomic Science and Technology. Ser.: Plasma Phys. 1, 257-260.

Pavlichenko, R. O., Zamanov, N. V. \& Kulaga, A. E. 2018 A high speed 140 ghz microwave interferometer for density fluctuation measurements in Uragan-2M stellarator. Problems of Atomic Science and Technology. Ser.: Plasma Phys. 6, 332-335.

PAUL VAN EETEN, et al. 2019 W7-X NBI beam dump thermocouple measurements as safety interlock. Fusion Eng. Des. 146, 1329-1333.

PEDERSEN, T. Sunn. et al. 2019 First divertor physics studies in Wendelstein 7-X. Nucl. Fusion 59, 096014.

SOROKIN, A. A. et al. 2004 Total electron-impact ionization cross sections of Helium. J. Phys. B: At. Mol. Opt. Phys. 37, 3215.

TRIPSKÝ, M. et al. 2017 A PIC-MCC code RFdinityld for simulation of discharge initiation 
by ICRF antenna. Nucl. Fusion 57. 126043.

VoitsenYa, V. S. et al. 2014 Progress in stellarator research in Kharkov IPP. Phys. Scr.

T161, 014009.

WAUTERS, T. et al. 2018 Wall conditioning by ECRH discharges and He-GDC in the limiter phase of Wendelstein 7-X. Nucl. Fusion 58, 066013.

WAUTERS, T. et al. $2020 \mathrm{Wall}$ conditioning in fusion devices with superconducting coils Plasma Phys. Control. Fusion 62, 034002.

WOLF, R. C. et al. 2019 Electron-cyclotron-resonance heating in Wendelstein 7-X: A versatile heating and current-drive method and a tool for in-depth physics studies. Plasma Phys. Control. Fusion 61, 014037.

ZALESKIJ, Yu. G. et al. 1989 Start-up of HF plasma discharge in the Uragan-3 torsatron. Fiz.

Plazmy 15, 1424-1429. (in Russian). 